\title{
PerCursos
}

\section{Democratização e Tecnocapitalismo: O Brasil na Era Neoliberal}

\begin{abstract}
Resumo
Neste ensaio, apresentaremos algumas considerações críticas sobre a problemática da democratização no contexto histórico da sociedade civil neoliberal e do desenvolvimento do tecnocapitalismo no Brasil (1990-2020). O objetivo é expor elementos da sociabilidade virtual e da infosfera (big data, redes sociais, pós-verdade etc.) e seus impactos significativos na esfera pública, na operação dos intelectuais e na organização da cultura. Partindo de autores como Coutinho, Berardi, Castells e Kerckhove, apresentaremos a hipótese de que, com a constituição do tecnocapitalismo no Brasil (a expansão da Internet na década de 2000 e o desenvolvimento das plataformas virtuais e das redes sociais na década de 2010), surgiu uma nova estrutura ideológica para além das mídias tradicionais, que alterou a dinâmica da organização da cultura e do modo de operação da luta pela hegemonia social (e política) das classes sociais e seus intelectuais orgânicos.
\end{abstract}

Palavras-chave: Intelectuais. Infosfera. Neoliberalismo. Democracia. Brasil.

\author{
Giovanni Alves \\ Doutor em Ciências Sociais pela \\ Universidade Estadual de \\ Campinas - UNICAMP. Professor \\ da Universidade Estadual Paulista \\ - UNESP/Campus de Marília. \\ Brasil \\ alvesgiovanni61@gmail.com
}

\section{Luís Henrique do Nascimento Gonçalves}

Doutorando em Psicologia Social na Pontifícia Universidade

Católica - PUC/SP.

Brasil

luishng72@gmail.com

\author{
Ana Celeste Casulo \\ Mestranda em Psicologia pela \\ Universidade Estadual Paulista - \\ UNESP/ Campus de Assis. \\ Brasil \\ ana.celeste590@gmail.com
}

\section{Para citar este artigo:}

ALVES, Giovanni; GONÇALVES, Luís Henrique do Nascimento; CASULO, Ana Celeste. Democratização e Tecnocapitalismo: O Brasil na Era Neoliberal. Revista PerCursos, Florianópolis, v. 21, n.45, p. 24 - 49, jan./abr. 2020. 


\title{
Democratization and Technological Capitalism: Brazil in the Neoliberal Era
}

\begin{abstract}
In this essay we will present some critical considerations on the problem of democratization in the historical context of neoliberal civil society and the development of technological capitalism in Brazil (19902020). Our goal is to expose the elements of virtual sociability (big data, social networks, post-truth) and their significant impacts on the public sphere and on the operation of intellectuals and the organization of culture. According to authors such as Coutinho, Berardi, Castells and Kerckhove, we will present the hypothesis that, with the constitution of technocapitalism in Brazil (the expansion of the Internet in the 2000s and the development of virtual platforms and social networks in the 2010s), it appeared a new ideological structure in addition to traditional media, which changed the dynamics of the organization of culture and the way in which the struggle for social (and political) hegemony of social classes and their organic intellectuals operated.
\end{abstract}

Keywords: Intellectuals. Info-sphere. Neoliberalism. Democracy. Brazil. 


\section{Apresentação}

Nosso objetivo é expor alguns elementos da nova sociabilidade virtual e seus impactos significativos na esfera pública ${ }^{1}$ vinculados às operações dos intelectuais na organização da cultura e da democratização do Estado. Entre os anos 1990 e 2020, ocorreram importantes transformações históricas no Brasil por conta do desenvolvimento do capitalismo global ${ }^{2}$. Nesse período, tivemos o desenvolvimento da sociedade civil neoliberal e a disseminação de novos elementos de sociabilidade virtual vinculados às transformações do tecnocapitalismo. O conceito de "tecnocapitalismo" foi desenvolvido por Luis Suarez-Villa $(2009 ; 2012)$ e o relaciona à globalização e ao crescente poder das empresas de tecnologia. Algumas das principais corporações que dominam o mercado do tecnocapitalismo são chamadas de FAANG (Facebook, Amazon, Apple, Netflix e Google), representantes não somente do novo cenário do capitalismo global, como também das relações de consumo e comportamento social do mundo global.

As corporações que controlam o tecnocapitalismo alteram as formas de poder político e de produção, circulação e acumulação ao renovarem as formas de apropriação de recursos intangíveis - como criatividade e novos conhecimentos -, principalmente através da propriedade intelectual e da infraestrutura tecnológica. Essa perspectiva sobre a globalização e os efeitos do tecnocapitalismo também leva em consideração (1) as desigualdades criadas entre as nações na vanguarda do tecnocapitalismo e aquelas que não dominam o poder tecnológico (UNCTAD, 2019); (2) a crescente importância dos fluxos de fuga de cérebros entre nações (OCDE, 2008) e (3) a ascensão do complexo técnico-militar-corporativo que está substituindo rapidamente o antigo complexo militarindustrial da segunda metade do século XX (NADER, 1997; SIEVER, 1997; ZINN, 1997).

\footnotetext{
1 De acordo com Habermas (1984), a esfera pública seria a dimensão na qual os assuntos públicos são discutidos pelos atores públicos e privados. Tal processo culminaria na formação da opinião pública que, por sua vez, agiria como uma força oriunda da sociedade civil em direção aos governos, no sentido de pressioná-los de acordo com seus anseios. Para Habermas, a noção de esfera pública tem como aspectos básicos: (a) Discursividade e argumentação: dominada pelo uso da razão, a obtenção de consenso acontece pelo convencimento racional dos antagonistas. (b) Publicidade: o objeto debatido e os argumentos apresentados ganham exposição ou visibilidade. (c) Privacidade: enquanto participante do debate, cada um vale somente pelos argumentos e pela capacidade de argumentar.

2 Por "capitalismo global", entendemos o capitalismo desenvolvido a partir da década de 1990 com a globalização dos mercados e o surgimento da Internet (ALVES, 2018).
} 
Diante desse novo período histórico, nossa hipótese é que as mudanças tecnológicas "de fundo" da vida social, por conta das novas tecnologias da informação e comunicação, redefiniram, de modo qualitativamente novo, o papel dos intelectuais e da organização da cultura. A partir disso, colocam-se imensos desafios para a democratização política no Brasil, por conta da fragilidade histórica da cultura democrática e das dificuldades de constituição do espaço público no país³.

\section{As mutações sociometabólicas (e políticas) do tecnocapitalismo}

O tecnocapitalismo e sua infosfera possuem características e determinações que corroem as bases fundamentais do espaço público e das possibilidades efetivas de participação política numa democracia liberal. Principalmente porque operam vinculadas à crise social que emerge da intensificação da precarização do trabalho, que por sua vez introduz novos elementos disruptivos no plano da consciência social (ALVES, 2013; ANTUNES, 2019; MOROZOV, 2018). A Infosfera é um neologismo que faz referência a um complexo ambiente constituído por todas as entidades informacionais, suas propriedades, interações, processos e demais relações (FLORIDI, 2006).

Nesse sentido, Manuel Castells (2015) e Franco "Bifo" Berardi (2017) - entre outros $^{4}$ - constataram importantes mutações políticas e culturais decorrentes do tecnocapitalismo. Castells (1996) foi pioneiro em tratar dos impactos das novas

\footnotetext{
${ }^{3}$ A democratização tem sido, desde sempre, uma questão fundamental da política no Brasil, tendo em vista o histórico brasileiro demarcado por regimes autocráticos. Consideramos que o processo de democratização ocorre em função do desenvolvimento da sociedade civil e do espaço público, com a formação dos intelectuais e da organização da cultura. Utilizamos o conceito de intelectuais de acordo com Gramsci (1985), que distingue os "intelectuais orgânicos" dos "intelectuais tradicionais". Por "intelectuais orgânicos", ele denomina aqueles que promovem a organização da cultura na sociedade civil. Por "sociedade civil", diz Gramsci, entende-se o "conjunto dos organismos vulgarmente ditos privados que correspondem à função de hegemonia que o grupo dominante exerce em toda a sociedade" (GRAMSCI, 1985, p. 142). Gramsci opõe sociedade civil à sociedade política (o Estado no sentido estrito do termo), da qual ela constitui a "base", o conteúdo ético. A sociedade civil é um campo complexo no qual opera, a ideologia da classe dominante, que abrange todos os ramos da ideologia (arte, ciência, economia, direito, etc.); a concepção de mundo difundida em todas as camadas sociais para vinculá-las à classe dirigente. Advém daí seus diferentes graus qualitativos: filosofia, religião, senso comum e folclore (COUTINHO, 1989, p. 25).

4 Vários autores apontaram mudanças essenciais no metabolismo social do capitalismo no século XXI por conta das mutações provocadas pela nova base tecnológica da vida social (BAUMAN, 2001; BYUNG-CHUL, 2013; LIPOVETSKY, 2011; ROSA, 2019).
} 
tecnologias informacionais. Para ele, a economia global se caracteriza hoje pela rede, fluxo e troca quase instantâneas de informação, capital e comunicação cultural e que atuam, em grande medida, fora das regulamentações nacionais (CASTELLS, 1999). O sociólogo espanhol também analisa (CASTELLS, 2001) a Internet como espinha dorsal das sociedades globais e da nova economia mundial, buscando com isso desvendar sua lógica, suas imposições e a liberdade que ela nos dá.

Como observou Castells, com a infosfera, surge um novo elemento na construção das democracias, para o bem ou para o mal, que são as redes sociais. Por exemplo, o que existe em comum entre as eleições brasileiras de 2018, a corrida presidencial de Trump e o Brexit etc. (todas posteriores à escrita de Castells), é o uso de múltiplas frentes de plataformas virtuais que transferem o debate político ao ciberespaço e deixam as mídias tradicionais cada vez mais em segundo plano. De qualquer modo, Castells constatou que a nova sociabilidade virtual tem um "efeito paradoxal" no processo político das democracias liberais. Ao destacar as múltiplas crises da atualidade, o autor põe-se a pensar sobre o que ele chama de uma crise mais profunda, que é a ruptura da relação entre governantes e governados, produzindo a "total decomposição do sistema político" (CASTELLS, 2015, p. 8). Diz ele que tal colapso da democracia liberal, enquanto modelo político de representação e governança, abre espaço ao pós-liberalismo articulado por partidos e movimentos nacionalistas, xenofóbicos e críticos à política tradicional, com sua aparente defesa da ordem revestindo suas práticas violentas. Portanto, pode-se ir mais a fundo e salientar que a presença da infosfera na formação dos intelectuais e da organização da cultura, nas condições do tecnocapitalismo, tem contribuído para tais mudanças disruptivas (ou rupturais) na esfera da política.

Por sua vez, desde a década de 2000, o filósofo italiano Franco Berardi (2017) também tem tratado dos impactos das mudanças sociometabólicas promovidas pelo tecnocapitalismo na esfera da política. Fazendo contraponto a Castells, Berardi diria que o problema fundamental não é político, mas cognitivo. Para ele, por exemplo, na medida em que o papel do semiológico e do financeiro tornaram-se dominantes, constitui-se o que ele denominou de "semiocapitalismo" (o capitalismo sob a dominância do semiológico). Diz Berardi: 
Chamo semiocapitalismo à configuração atual da relação entre linguagem e economia. Nessa configuração, a produção de qualquer bem, material ou imaterial, pode ser traduzida em uma combinação e recombinação de informações (algoritmos, figuras, diferenças digitais). A semiotização da produção social e do intercâmbio econômico implica uma profunda transformação no processo de subjetivação. A infosfera atua diretamente no sistema nervoso da sociedade, afetando a psicosfera e a sensibilidade em particular. Por esse motivo, a relação entre economia e estética é crucial para entender a atual transformação cultural. (BERARDI, 2017, p. 127-128).

A categoria de "semiocapitalismo", criada por Franco Berardi, visa decifrar a produção da subjetividade e os novos dispositivos de servidão voluntária, que não se desdobram mais na dimensão exclusiva da imagem, mas penetram nos interstícios da própria linguagem até atingir seu núcleo mais profundo e inconsciente. Afirma Berardi que, na era da pós-verdade, tudo pode ser dito e transformado em "verdade irrefutável". As mutações cognitivas decorrentes da era da digitalização e da predominância da financeirização no semiocapitalismo contribuem para o cenário distópico de Berardi. Nessa perspectiva, de acordo com ele, o "fim da referencialidade e a indeterminação do valor", implodem a esfera da política e a própria democracia liberal-representativa. Berardi apoia-se em Jean Baudrillard, que há décadas tinha observado os efeitos das mudanças sócio-técnicas e culturais das sociedades do capitalismo tardio. O que Baudrillard observou na década de 1980 tornou-se terrivelmente atual com o semiocapitalismo:

O ponto crucial da crítica de Baudrillard é o fim da referencialidade e (in)determinação do valor. Na esfera do mercado, as coisas não são consideradas do ponto de vista de sua utilidade concreta, mas de sua intercambialidade e seu valor de troca. Da mesma forma, na esfera da comunicação, a linguagem é comercializada e valorizada como desempenho. É a eficácia, e não o valor da verdade, a regra da linguagem na esfera da comunicação. É a pragmática, e não a hermenêutica, a metodologia para entender a comunicação social, particularmente na era das novas mídias. (BERARDI, 2017, p. 175). 
Tais mutações cognitivas do semiocapitalismo - o estágio em que o signo linguístico teria se emancipado de toda referencialidade para percorrer uma espacialidade na qual a abstração domina -, têm impacto danoso na esfera pública e, portanto, na democracia liberal. Com isso, se comprometeria, de vez, as possibilidades de emancipação política. Berardi também se detém naquilo que expressa um dos elementos sociometabólicos do tecnocapitalismo: a emergência da "pós-verdade". A pós-verdade, como, por exemplo, as fake news disseminadas nas plataformas virtuais, são produtos exacerbados do fim da referencialidade, tanto na economia como no campo linguístico. Essas mudanças, segundo ele, fazem parte de mutações estruturais do campo da produção. No espelho da produção,

[...] a necessidade, o valor de uso, o referente "não existem": são apenas conceitos produzidos e projetados em uma dimensão genérica pelo desenvolvimento do próprio sistema de valores de troca. O processo de autonomização da moeda, que é a principal característica do capitalismo financeiro, pode ser incluído na estrutura geral da emancipação da semiose da referencialidade. (BERARDI, 2017, p. 172-173).

Ainda para Berardi, não é a dominância do capital financeiro que explica a perda da referencialidade, mas o contrário: o poder do capital financeiro representa apenas a “emancipação da semiose da referencialidade". Na perspectiva da comunicação, o fim da referencialidade introduz, de maneira radical, a autonomia do signo, com impactos na produção de conteúdos intangíveis, que definem o vínculo com a realidade. Isso, por sua vez, determinaria as formas da busca de rentabilidade por um capital que vem preterindo a esfera de produção para se concentrar na esfera financeira. Quando a referencialidade evapora, o que também termina é o vínculo argumentativo, abrindo caminho para a fabricação de sujeitos movidos por sinais vazios e abstratos que impactam totalmente a dimensão afetiva e sensível.

Ao adotar o paradigma da linguagem em sua crítica do sociometabolismo do capital, Franco Berardi se distancia da explicação marxista clássica. Assim, ele inverte a determinação capaz de explicar aquilo que denominará de "perda da referencialidade" e 
que caracteriza o semiocapitalismo (o capitalismo da semiose). Ao invés de explicá-la pelo poder do capital financeiro ou pela dominância do fetiche do capital nas condições históricas do capitalismo global (o paradigma da produção), ele a explica pela “emancipação da semiose da referencialidade". Ele não explica o que provocou a autonomização do signo, o "fim da referencialidade e a (in)determinação do valor" (Baudrillard). Nessa sua perspectiva, seria a linguagem - e não as relações sociais de produção - que constitui o mundo humano. Ao invés da economia explicar a linguagem (a evaporação da referencialidade), é a linguagem (o “capitalismo da semiose”) que explica a economia.

Nessas condições do tecnocapitalismo, a possibilidades da democratização da vida política e social torna-se deveras problemática, tendo em vista que seu processo implica a formação de individualidades capazes de - por meio de processos político-democráticos baseados no vínculo argumentativo - exercer a tomada de decisões. Berardi diz que quebrar essa "nova forma de feitiço" - ou "fetichismo da tecnologia" - constitui o desafio mais árduo e difícil de qualquer projeto de democratização política e social. 0 perigo é que o rompimento e interversão do processo de significação social das determinações da materialidade acabem sendo aceitos pelos sujeitos como a "realidade" efetiva, sem chance de escapar dessa colonização cada vez mais profunda.

A poluição informacional e o aprimoramento da manipulação de mercado por meio de recursos captológicos ${ }^{5}$ configuram uma verdadeira "economia da atenção" dos indivíduos, promovendo mudanças significativas que corroem não apenas a base da democracia liberal, mas qualquer perspectiva de um processo de democratização mais amplo:

Hoje, a tecnologia digital se baseia na inserção de memes neurolinguísticos e dispositivos automáticos na esfera da cognição, na psique social e nas formas de vida. Metaforicamente e literalmente, podemos dizer que o cérebro social está passando por um processo de

\footnotetext{
${ }^{5}$ Captologia é o acrônimo para computador como tecnologia persuasiva; é o estudo de computadores como tecnologias persuasivas. "Isso inclui o design, a pesquisa e a análise de programas de produtos de computação interativa (como a Web, software de desktop, dispositivos especializados etc.) criados com a finalidade de alterar as atitudes ou comportamentos das pessoas" (WIKIPEDIA, 2020).
} 
ligação, mediado por protocolos linguísticos imateriais e dispositivos eletrônicos. Na medida em que os algoritmos se tornam cruciais na formação do corpo social, a construção do poder social muda do nível político de consciência e vontade para o nível técnico dos automatismos localizados no processo de geração de trocas linguísticas e na formação psíquica e orgânica dos corpos. (BERARDI, 2017, p. 34).

Portanto, o que Berardi ressalta nos novos processos de subjetivação é a influência decisiva que foi estabelecida entre as esferas da linguagem e da economia gerando o semiocapitalismo, com a massa de cidadãos-consumidores se movendo dentro desse processo de estetização do mundo.

\section{Tecnocapitalismo e "miséria brasileira"}

A problemática que pretendemos expor neste artigo - sem pretensões de apontar uma solução - é: quais os impactos, na democracia brasileira, das mutações sociometabólicas (políticas e cognitivas) promovidas pelo tecnocapitalismo?

Em primeiro lugar, ressaltaremos que o Brasil se caracteriza pela fragilidade estrutural da cultura democrática e pela miséria do espaço público e da socialização da política. Tal fragilidade estrutural da democracia decorre de elementos históricos da formação brasileira de cariz escravista-colonial, constituindo a "miséria brasileira" (CHASIN, 1999, p. 85). Depois, num segundo momento, distinguiremos dois períodos históricos do Brasil moderno: o (1) período de renascimento liberal-democrático na transição para a "Nova República” (1978-1989), onde tivemos o despertar da sociedade civil brasileira, com movimentos pela socialização da política, o associativismo e a explosão do sindicalismo e movimentos coletivos sociais; e (2) o período da "Nova República" fundada pela Constituição de 1988, com o surgimento e desenvolvimento, a partir da década de 1990, da "sociedade civil neoliberal" (1990-2018). Na nova etapa histórica do Estado neoliberal, podemos destacar, no plano social, a formação do novo (e precário) mundo do trabalho; e depois, a partir da década de 2000, a disseminação do tecnocapitalismo na vida cotidiana, alterando de modo qualitativamente novo a organização da cultura e o papel dos intelectuais. 
O Brasil é um país capitalista de formação colonial-escravista, periférico, dependente e de industrialização hipertardia. A objetivação do capitalismo no Brasil a partir do século $\mathrm{XVI}$, ocorreu primeiro como capitalismo agrário-comercial; e depois, como capitalismo urbano-industrial de cariz hipertardio. A industrialização ainda era bastante incipiente em fins do século XIX, tornando-se mais desenvolvida só em meados do século XX. As principais atividades econômicas estavam associadas à exportação de produtos agrícolas, dentre eles o café. Foi apenas entre os anos de 1930 e 1945, que o país transitou do modelo agrário-exportador para o modelo urbano-industrial. Até 1950, o Brasil era um país de população, predominantemente, rural. Em 1940, apenas 31\% da população brasileira vivia em cidades. Foi a partir de 1950 que o processo de urbanização se intensificou com o desenvolvimento da "industrialização pesada” (MELLO, 2009).

De acordo com Francisco de Oliveira (2013), o capitalismo brasileiro se desenvolveu sob "formas de exceção", isto é, formas particulares de objetivações histórico-concretas do capitalismo na periferia que o distinguem efetivamente de outras formações capitalistas ocidentais. Tais "formas de exceção" constituem a formação histórica brasileira enquanto sistema capitalista na sua periferia (a "exceção" é em relação a um modelo referencial clássico e mesmo tardio de desenvolvimento capitalista, como, por exemplo, Inglaterra e França, ou mesmo Alemanha e Itália).

As "formas de exceção" têm uma dinâmica de persistência histórica que podemos denominar "miséria brasileira" (CHASIN, 1999; MARX, 2010). Na medida em que não ocorreu no Brasil, desde o século XVI, nenhuma revolução social de "baixo" para "cima”, tais "formas de exceção" se reproduziram (e se transfiguraram) no interior do próprio desenvolvimento do Estado brasileiro em sentido ampliado (sociedade civil e sociedade política):

1. De forma bastante esquemática, podemos dizer que, até meados do século XIX, sob o capitalismo agrário-comercial, a sociedade civil foi quase inexistente no Brasil, apesar de existirem alguns órgãos de imprensa e rudimentos de associações (clubes políticos, sociedades recreativas, associações de socorros mútuos, etc.). Num país predominantemente agrário, a sociedade civil foi incipiente até a primeira metade do século XX. Na verdade, a sociedade brasileira se constituiu organicamente no interior do 
modo de produção capitalista em sua fase mercantil, objetivando-se com (e pelo) mercado mundial em sua forma moderna ${ }^{6}$. Como capitalismo colonial na sua origem histórica, o capitalismo brasileiro articulou dialeticamente (e paradoxalmente), agrarismo escravocrata com produção de mercadorias. Até 1888, uma parcela significativa de escravos produzia mercadorias para o mercado mundial sob a hegemonia do capital agrário-mercantil, que depois iria se tornar o embrião do capital industrial (principalmente a partir da República, em 1889). Por quase quatro séculos, a partir da colonização portuguesa no começo do século XVI até os primórdios do capitalismo agroexportador no final do século XIX, não ocorreu nenhuma mudança estrutural no sistema de propriedade agrária (o que constitui um elemento de reforço da persistência histórica da “miséria brasileira”). Apesar da proclamação da independência política nacional em 1822, a estrutura econômico-social brasileira não sofreu grandes transformações.

2. O escravismo no Brasil, abolido apenas nas últimas décadas do século XIX (1888), imprimiu a sua marca cultural no desenvolvimento da sociedade e na organização da cultura brasileira. De acordo com Carlos Nelson Coutinho, o escravismo brasileiro impediu o desenvolvimento da sociedade civil e, por conseguinte, tornou historicamente débil a cultura democrática no Brasil. Apesar de importar instituições e valores do capitalismo liberal, existiu no Brasil, em quase todo o século XIX, um regime escravista que deformou a estrutura do metabolismo social da modernidade brasileira, impedindo utilizando a perspectiva gramsciana - a formação de intelectuais orgânicos e tornando predominantes os intelectuais tradicionais e sua cultura ornamental (e escapista), à sombra do poder oligárquico (COUTINHO, 2011, p. 19).

Portanto, aquilo que denominamos de fragilidade estrutural da democracia e a miséria do espaço público e da socialização da política no Brasil originaram-se das duas “formas de exceção" destacadas acima (a gênese colonial e a formação escravista). Os processos políticos de mudanças históricas no Brasil - em 1822, com a Proclamação da

\footnotetext{
${ }^{6}$ Existe uma controvérsia sobre a caracterização da formação social brasileira na sua origem histórica. Por exemplo, Jacob Gorender interpretou o Brasil como representando, na sua origem, um novo modo de produção escravista colonial (GORENDER, 2016). Por outro lado, Nelson Werneck Sodré salientou que o Brasil, até meados do século XIX, era feudal e escravista (apenas em 1888 aboliu-se a escravidão no Brasil) (SODRÉ, 1997). Caio Prado Jr. observou que o Brasil, desde o descobrimento em 1500, era uma formação social identificada como “capitalismo colonial” (PRADO Jr., 1985, p. 146).
} 
Independência do Brasil; em 1889, com a Proclamação da República; em 1930, com a Revolução de 1930; em 1937, com o Estado Novo; em 1964, com o Golpe Militar e inclusive em 2016, com o Impeachment de Dilma Rousseff - têm sido desde sempre, processos de reformas "pelo alto", sob o domínio do poder oligárquico burguês (é o que Gramsci denominou de "revolução passiva" ou "revolução-restauração"). Esse traço característico com que convive o capitalismo brasileiro - o que denominamos alhures de “pulsão golpista” (ALVES, 2016) - é um elemento proeminente da persistência da “miséria brasileira". O que demonstra que o traço ontogenético das "formas de exceção" possui persistência secular e diz respeito à forma de estruturação do poder oligárquico no Brasil, que perdurou na forma da República liberal-democrática, reforçando-se com a República neoliberal.

Le mort saisit le vif! [o morto se apoderando do vivo], diria Marx7. A força de inércia da "miséria brasileira" manifestou-se, por exemplo, nos afetos do ressentimento e do ódio de classe (o desprezo pelo pobre e o medo da "revolta escrava") que mobilizaram subjetivamente a "classe média" tradicional brasileira sob a hegemonia da classe dominante, nos momentos históricos de transformação social - por exemplo, o período do "populismo" de cunho trabalhista, com Getúlio Vargas e João Goulart (19501964), e o período do dito "populismo" petista com Lula e Dilma (2003-2016) (KEHL, 2011).

\section{Década de 1980: o despertar da sociedade civil liberal-democrática no Brasil}

Com o desenvolvimento do capitalismo urbano-industrial no Brasil, intensificou-se a socialização da política. A nova sociedade civil liberal-democrática desenvolveu-se após a derrubada de Getúlio Vargas e o fim do Estado Novo em 1945. Ela prossegue mesmo sob o clima autoritário da ditadura militar a partir de $1964^{8}$. A batalha das ideias pela

\footnotetext{
7 Ao tratar do desenvolvimento da Alemanha, um país de capitalismo tardio, Marx observou, no Prefácio à Primeira Edição de O Capital (1867), o peso das gerações mortas: "Padecemos não apenas por causa dos vivos, mas também por causa dos mortos" (MARX, 2013, p.32). Anteriormente, ele tratou disso no 18 Brumário de Luís Bonaparte (1851-1852), ao discutir as lutas de classes na França que levaram à ascensão de Luís Bonaparte: “A tradição de todas as gerações mortas oprime, como um pesadelo, o cérebro dos vivos" (MARX, 2011, p. 32).

8 O termo "liberal-democrático" no Brasil possui significações particulares deveras paradoxais: historicamente, o liberalismo no Brasil teve um caráter conservador e flertou com o escravismo no século
} 
conquista da mentalidade da "nova classe média" e do novo proletariado urbanoindustrial tornou-se fulcral9. Naquela época, em fins da década de 1960, sob o regime da ditadura civil-militar, a classe dominante brasileira deu continuidade à organização dos seus aparelhos privados de hegemonia (iniciados com os Diários Associados, de Chateaubriand nos anos 1930), com a fundação, por exemplo, da TV Globo em 25 de abril de 1965, um ano após o golpe militar; e o lançamento da revista Veja pela Editora Abril (em 11 de setembro de 1968). Tais importantes aparelhos privados de hegemonia nasceram para disputar a consciência contingente (os “corações e mentes") da nova classe média e das classes subalternas no seio da sociedade civil liberal-democrática oriunda do salto de modernização conservadora no Brasil. Tanto a TV Globo, como a revista Veja, tornaram-se "intelectuais orgânicos" funcionais ao bloco no poder oligárquico no Brasil (COUTINHO, FREIRE FILHO; PAIVA, 2014).

Na década de 1980, com a dita "redemocratização", a sociedade brasileira presenciou a explosão de organizações da sociedade civil. De início, de 1978 a 1980, tivemos o marco histórico de impulsionamento da luta de classes no seio da sociedade civil brasileira contra a ditadura militar. Foi nesse período histórico, de 1978-1980, que tivemos as greves dos operários metalúrgicos do $A B C$ paulista, à época a região mais industrializada do País. A luta sindical dos metalúrgicos do $A B C$ foi um dos principais símbolos do despertar da luta social no Brasil naquela época. A luta contra o "arrocho salarial" e pelas liberdades democráticas mobilizou outras categorias de trabalhadores assalariados, caracterizando a eclosão do "novo sindicalismo", que se tornou uma força social proeminente da luta pela redemocratização do País. Foi na década de 1980 que

XIX; e a democracia sempre foi um valor ornamental, tal como a cultura escapista, restrita ao funcionamento das instituições democráticas formais de conteúdo oligárquico. Por isso, podemos dizer que, mesmo sob a ditadura militar (1964-1984), existia, no limite, uma sociedade civil liberal-democrática, pois as instituições da democracia liberal "funcionavam", tais como o Congresso Nacional, o Poder Judiciário, os sindicatos (sob intervenção do Ministério do Trabalho), os jornais, revistas e TV (sob censura do Ministério da Justiça).

9 Entre 1945 e 1980, o Brasil sofreu intenso processo de urbanização, expansão econômica e industrialização. Durante esse período, a classe média brasileira se expandiu vigorosamente em virtude da diversificação da estrutura social, com a criação de ocupações intermediárias e crescimento da burocracia e dos serviços oferecidos pelo Estado (o que denominamos de "nova classe média"). Portanto, o perfil da classe média brasileira foi mudando, ao longo desse período, diminuindo a participação de pequenos proprietários (velha classe média) e aumentando o percentual de assalariados (nova classe média). Esse processo de desenvolvimento da classe média brasileira, em meados do século XX, é muito bem descrito por Quadros (1991). 
ocorreu a fundação do PT (Partido dos Trabalhadores), a e da CUT (Central Única dos Trabalhadores), expressões políticas organizativas do novo sindicalismo e das oposições sindicais. Nesse período de transição à democracia, tivemos a disseminação das associações de bairros, comunidades eclesiais de base etc., organismos privados da sociedade civil que, durante a década de 1980, alavancaram a candidatura de Luís Inácio “Lula" da Silva (PT) nas eleições presidenciais de 1989. No auge de "explosão" da sociedade civil liberal-democrática, tivemos, em 5 de outubro de 1988, a promulgação da Nova Constituição da República Federativa do Brasil, a denominada "ConstituiçãoCidadã", uma das mais avançadas constituições brasileiras em termos de garantias de direitos sociais e políticos.

Entretanto, a derrota política do candidato da Frente Brasil Popular (PT-PCdoB), Luís Inácio “Lula” da Silva, em 1989, e as mudanças estruturais do capitalismo brasileiro conduzidas pelos governos neoliberais de Fernando Collor de Mello (1990-1992) e Fernando Henrique Cardoso (1994-2002), contribuíram para integrar o Brasil à mundialização do capital a partir da década de 1990. Surgiu o que podemos denominar “sociedade civil neoliberal”, um novo conteúdo de materialidade política e cultural que condicionou, sob a hegemonia das mídias tradicionais, a disputa ideológica na sociedade civil.

Nesse contexto, com a constituição do tecnocapitalismo, surgiu uma nova estrutura ideológica, para além das mídias tradicionais. Isso alterou a dinâmica da organização da cultura e o modo de ser da hegemonia social (e política) das classes dominantes. Não apenas mudanças de conteúdo da ideologia propriamente dita (a forma das fake news sob o conteúdo da "pós-verdade" ou perda da referencialidade), mas da própria “estrutura ideológica”. Isto é, as organizações que a criam e a difundem (redes sociais etc.), e do próprio "material” ideológico, ou seja, os instrumentos técnicos de difusão da ideologia (por exemplo, a internet acoplada aos smartphones).

Assim, a sociedade civil neoliberal institui a sociabilidade virtual e a "economia da atenção". Não se trata apenas de mudanças dos instrumentos técnicos de difusão da 
ideologia, mas sim, mudanças da "pele"10 da cultura - a cultura virtual - que operam mudanças cognitivas "de fundo". Tais mudanças contribuíram para um salto qualitativamente novo na forma de adequação dos intelectuais ao sistema de poder da classe dominante.

Com isso, por um lado, temos a intensificação, ampliação e fragmentação do campo da sociedade civil, entendida como um campo de desenvolvimento dos aparelhos privados de hegemonia. Como salientamos acima, a sociedade civil é o território material dos intelectuais orgânicos, os intelectuais que necessariamente - sem perder sua autonomia e a independência de pensamento - lutam pela hegemonia política e ideológica do grupo social que representam através (e no seio) dessas formas autônomas de criação e de difusão da cultura. Ao se desenvolver a sociedade civil, criam-se as condições para o desenvolvimento dos intelectuais orgânicos enquanto organizadores de cultura (COUTINHO, 2011).

\section{Tecnocapitalismo e o ocaso da sociedade civil liberal-democrática}

A nova pele da sociedade civil neoliberal representa o ocaso da democracia liberal nas condições históricas de crise do capitalismo global ${ }^{11}$. Dadas as nossas fragilidades estruturais na cultura democrática por conta da nossa formação histórico-social, o tecnocapitalismo se acopla à "miséria brasileira" para, ao produzir (e reproduzir) a dominação de classe, moldar sujeitos inaptos para a recepção crítica de conteúdo. É claro

\footnotetext{
${ }^{10}$ A ideia de "pele" extraímos de Derrick de Kerckhove. Diz ele, tratando das mudanças tecnoculturais produzidas pelo design industrial dos novos instrumentos tecnoinformacionais: "Existem claramente mais questões no design além de servir para conter e seduzir. Num sentido mais amplo, o design desempenha um papel metafórico, traduzindo benefícios funcionais em modalidades cognitivas e sensoriais. $O$ design encontra a sua forma e o seu lugar como uma espécie de som harmônico, um eco da tecnologia. Frequentemente faz eco do caráter específico da tecnologia e corresponde ao seu impulso básico. Sendo a forma exterior visível, audível ou texturizada dos artefatos culturais, emerge como aquilo a que poderíamos chamar 'a pele da cultura'." (KERCKHOVE, 2009, p. 172).

${ }^{11}$ Por crise do capitalismo global entendemos a crise da forma de capitalismo tardio desenvolvido a partir de 1990, caracterizada pela globalização da produção e comércio mundial, financeirização da riqueza capitalista e adoção de políticas neoliberais (ALVES, 2018). O capitalismo global teve a sua etapa de ascensão histórica de 1990 a 2008. Entretanto, a partir do crash financeiro de 2008-2009, ele vive a sua etapa de crise estrutural, caracterizada por ROBERTS (2016), como sendo a terceira longa depressão do capitalismo industrial. Com a pandemia do novo coronavírus, a crise do capitalismo global deve aprofundar-se na década de 2020.
} 
que isso se torna um problema global vinculado à própria sociedade de massas. Mas, no caso do Brasil, adquire uma dimensão trágica, tendo em vista a particularidade da "miséria brasileira". A tragédia brasileira se coloca nos termos da incapacidade estrutural de enfrentar os novos tempos de desenvolvimento capitalista.

A nova organização da cultura operada pela sociabilidade virtual implica uma nova organização da sociedade civil, que deve ser vista como parte do próprio conceito de Estado - no sentido ampliado (sociedade civil + sociedade política). Alteram-se os termos da organização da cultura como espaço de subjetivação dos indivíduos de classe, camadas e frações de classe. Com o tecnocapitalismo, a sociedade civil "virtual" torna-se um espaço privilegiado de subjetivação, sendo o território de formação do Estado e do sistema de poder do capital. Repõe-se a problemática dos intelectuais orgânicos na medida em que são eles que organizam a cultura como espaço da ideologia dominante. No sentido de Gramsci, a organização da cultura é função do intelectual orgânico e ele só pode exercê-la no território da sociedade civil. A infosfera torna-se mais um território "desterritorializado" - de disputa hegemônica visando legitimar (ou não) o poder da classe dominante, com impactos da dinâmica da sociedade política, mas principalmente da sociedade civil ${ }^{12}$.

Quando Gramsci constatou o surgimento da esfera da sociedade civil, ele indicou a necessidade de ampliar o conceito de Estado político do capital. A redefinição - de forma e conteúdo - da sociedade civil sob a sociabilidade virtual, impõe-nos, mais do que nunca, tratar de modo ampliado o conceito de Estado e, portanto, de sustentação do poder do capital como sistema de controle do metabolismo social. É nesse sentido que a dominação do capital implica tratar não apenas da esfera da coerção, mas - cada vez mais - da esfera do consentimento e consenso das classes subalternas.

Com a cibercultura e a nova materialidade da organização da cultura virtual, temos irremediavelmente a crise/refundação dos intelectuais orgânicos (a crise de direção

\footnotetext{
12 Por exemplo, temos hoje um elenco de novos “intelectuais orgânicos" do capital, verdadeiros "profissionais" das redes sociais, influencers, YouTubers (com vídeos com milhões de visualizações), "gurus" como Olavo de Carvalho etc. (vide a reportagem "Cinco dos dez canais que explodiram no ranking do YouTube durante as eleições são de extrema-direita". Disponível em: <https://theintercept.com/2019/08/28/ranking-youtube-extrema-direita/>. Acesso em: 2 mar. 2020).
} 
ideológica propicia o surgimento de ideologias neofascistas). Na verdade, o surgimento das redes sociais aprofunda a batalha no seio da estrutura ideológica e cultural; ao mesmo tempo, corrói o espaço público como referência da operação da democracia liberal.

\section{A nova pele tecnológica da sociedade civil neoliberal}

O novo metabolismo da barbárie social, intensificado a partir da crise do capitalismo global, tem, como principal característica, o acirramento da manipulação social por meio da nova base tecno-informacional, produzindo aquilo que Franco Berardi identificou como deterioração cognitiva e comprometimento da capacidade de pensamento crítico dos sujeitos. Em nosso tempo histórico, com as tecnologias da informação e da comunicação (TICS), elevou-se a um patamar superior a (re)produção do mundo da pseudoconcreticidade (KOSIK, 2015) e seus despistamentos, que têm como uma das principais bases materiais o uso de redes sociais e a disseminação dos aplicativos de informação e comunicação nos smarthphones. ${ }^{13}$

Para verificarmos essa afirmação, é preciso brevemente aqui dimensionar o uso das redes sociais no Brasil enquanto importante categoria do sociometabolismo digital. Segundo o Relatório 2019 Digital Global, o Brasil conta com 215,2 milhões de celulares para 211,6 milhões de habitantes (63\% pré-pagos), sendo 149,1 milhões deles usuários de internet (70\% da população contra $57 \%$ no mundo e percentualmente à frente da China, com 57\%). O que significa que a sociedade brasileira é uma das mais conectadas do mundo. Utilizando a Internet todos os dias (85\%), os brasileiros fazem desde buscas gerais (Google em $1^{\circ}$ lugar) a pesquisas voltadas à pornografia (xvideos.com em $10^{\circ}$. lugar). Mesmo sendo apenas $030^{\circ}$ país em velocidade de internet (30mbps contra a média mundial de 54,3 mbps), cerca de 140 milhões de brasileiros usam redes sociais (66,16\% da população, contra média mundial de 45\%) - quase todos (130 milhões)

\footnotetext{
${ }^{13} \mathrm{O}$ complexo dos fenômenos que povoam o ambiente cotidiano e a atmosfera comum da vida humana, que, com a sua regularidade, imediatismo e evidência, penetram na consciência dos indivíduos agentes, assumindo um aspecto independente e natural, constitui o mundo da pseudoconcreticidade (KOSIK, 2010, p. 15).
} 
principalmente através de smartphones (crescimento de 8,3\% em relação a 2018). O Brasil é o segundo país em tempo de uso de internet (9h29 por dia), quando a média mundial é de 6h42; sendo o $3^{\circ}$ lugar em tempo do seu uso em smartphones (4h45 por dia), quando a média mundial é de 3h14. Além disso, 75\% dos internautas brasileiros usam o Facebook (35\% na média mundial). Portanto, o Brasil é a terceira maior "população" da rede social, sendo o segundo colocado em engajamento (qualquer ação efetuada na rede social). No caso do Instagram, o Brasil é o $17^{\circ}$ colocado (40\% dos seus internautas, contra $15 \%$ na média mundial), ainda que seja o $3^{\circ}$ em crescimento em comparação a 2018. No YouTube, o canal brasileiro Kondzilla é o $4^{\circ}$ mais assistido, com mais de 4 bilhões de visualizações. De acordo com o Global Digital 2019, 89\% dos usuários de Internet no Brasil usam o aplicativo WhatsApp (WE..., 2019).

Para relacionar o quadro brasileiro com o conjunto de recursos de deterioração e comprometimento do pensamento crítico sobre o tecnocapitalismo, segundo o The Wall Street Journal, hoje sabemos que o Facebook pesquisou seus efeitos negativos na sociabilidade e na política partidária. De acordo com o veículo, o estudo da corporação reconhece que seus algoritmos "exploram a atração do cérebro humano pela divisão" e que "64\% de todas as associações extremistas de grupos são devidas a nossas ferramentas de recomendação".

Tais dados demonstram o alto nível de disseminação do tecnocapitalismo no Brasil, com implicações na vida social e política e na organização da cultura e formação dos intelectuais. Tem-se disseminado o uso político-ideológico do aplicativo de mensagens, por meio de bots, grupos, fake news etc. A breve consideração dos dados acima, referente à sociabilidade virtual no Brasil - sobretudo quando agregados mundialmente e em sua evolução nos últimos 15 anos - nos permite falar de uma expansão de meios tecnológicos digitais e informacional com impactos significativos no metabolismo social (individuação e socialização).

O que na década de 1990 tratou-se como sendo um "mundo virtual" em oposição a um "mundo real" apresenta-se hoje como uma nova - ubíqua e biunívoca - forma de estar no mundo e de interação dele conosco (BELLER, 2016; DANTAS, 2018; FUCHS, 2013). As novas tecnologias informacionais incrementam a multiplicação, a variedade e a 
interdependência de formas sociais de produzir, distribuir e consumir conteúdos digitais; ou ainda novas formas sociais de conhecer, informar, comunicar e cooperar em sociedade. Pode-se falar, de certa forma, de um "sociometabolismo digital", isto é, a troca metabólica do homem com outros homens por meios de dispositivos tecnoinformacionais, produzindo, desse modo, um novo espaço de sociabilidade.

Hoje, o processo de cooperação social tem a sua dimensão teleológica cada vez mais mediada, alocada e dependente de datificação (big data), com os computadores e smartphones, com a presença da inteligência artificial e algoritmos controlando a vida social por meio de uma infinidade de gadgets (dispositivos eletrônicos e digitais). Com isso, as "necessidades produtivas", ou a forma como as necessidades humanas se expressam em sociedade e aquelas que derivam da produção social (HOLZKAMPOSTERKAMP, 1990), desdobram-se, a partir da Quarta Revolução Industrial, como necessidades informacionais e digitais.

Por um lado, a divisão social do trabalho requer conjuntos específicos de significações (necessidades informacionais) que mobilizam o ser social em função da sua posição específica na reprodução social. Por sua vez, a convergência no espaço-tempo das significações (e da sua produção) proporcionadas pelas novas TICs demandam a percepção e a "capacidade de agir" para a satisfação de necessidades digitais. Em outras palavras, estar no mundo da reprodução social, significar e significar-se em sociedade, requer cada vez mais que a satisfação das necessidades humanas sociais ocorram mediadas pelas tecnologias digitais (HOLZKAMP, 1983).

A atualização (e radicalização) da pseudoconcreticidade tem apontado para o esfacelamento da sociabilidade nos espaços públicos (condomínios, shoppings; esvaziamento das ruas, da democracia e do comum/público). Eis as formas de corrosão do espaço público que, num país historicamente de fragilidade democrática, é deveras preocupante para a democratização da vida social. Temos, por exemplo, como formas de corrosão do espaço público, o ódio à política ("ninguém presta, não vale a pena se associar a nada"); o medo do "outro" - negro, pobre, gay, imigrante etc.; a incerteza social - adulteração e apagamento do passado, incompreensão do presente ("até 
quando?”) e medo do futuro; o cultivo de falsas esperanças - “não aja, alguém virá nos salvar" (militares, Deus etc.); no discurso do entretenimento - "don't worry, be happy".

Esse movimento vertiginoso assume dimensões trágicas pois ocorre num país de baixa escolarização, com a imposição do sociometabolismo digital tornando fluente a capacidade de o capital manipular, ocultando e desviar a atenção dos verdadeiros problemas da nação brasileira ${ }^{14}$. A saturação do ruído no processo de significação cognitiva compromete a formação da opinião pública, tendo impactos significativos naquilo que Habermas denominou de "esfera pública", tornando a compreensão de fatos sociais desgastante e incerta - e, por isso, não relevante (HABERMAS, 1984). É em resposta à intencional instabilidade cognitiva que surge a ascensão de novos think tanks e “influenciadores" - de Olavo de Carvalho aos pastores da Teologia da Prosperidade -, preenchendo essa lacuna. O resultado (projetado) é que, cada vez mais, estamos preferindo acreditar ou crer (dar crédito, valor antecipado) do que compreender - por exemplo, o fenômeno das fake news se constitui no interior dessa problemática mais ampla salientada acima.

Segundo Holzkamp (1983) e Sevignani (2019), na perspectiva dialética, a categoria da agência ou capacidade de agir [Handlungsfähigkeit], "significa o exercício de controle do indivíduo sobre as condições relevantes para a satisfação de suas necessidades por meio da participação na produção social”. A democracia pressupõe a capacidade de os cidadãos se encontrarem minimamente aptos ao discernimento das diferentes visões políticas em disputa e das consequências possíveis da sua implementação. Portanto, esse quadro geral é bastante ameaçador para a democracia liberal. Na verdade, a desestabilização do processo de significação social é um fenômeno do sociometabolismo da barbárie (ALVES, 2011), sendo a barbárie social (ou mutação cognitiva), a condição histórica da reprodução tardia do capital (ALVES, 2018).

\footnotetext{
14 Podemos salientar, por exemplo, a degradação dos biomas brasileiros pelos empreendimentos capitalistas. As significações falsas e diversionistas como a participação do ator Leonardo DiCaprio, do Greenpeace e outras ONGs e de brigadistas nos incêndios florestais, ainda que não possam inverter por completo a percepção de responsabilidade dos crimes ecológicos, objetivam glosar a capacidade da responsabilização dos agentes corporativos do capital.
} 


\section{Considerações finais}

No começo do século XXI, a sociedade liberal-democrática no Brasil deu lugar à sociedade civil neoliberal. Temos hoje, no país, uma crise dos valores liberaisdemocráticos, incapazes de conter as novas demandas sociais criadas contraditoriamente pelo desenvolvimento do capitalismo brasileiro - principalmente em sua etapa neodesenvolvimentista (2003-2016). Enquanto a sociedade civil liberal-democrática organizava-se a partir de órgãos coletivos ou aparelhos privados de hegemonia clássicos, que disputavam a formação da cidadania passiva por meio de partidos e sindicatos ou, ainda, por meio da "mídia alfabética" (jornais e revistas impressas; televisões e rádios), o metabolismo social da sociedade civil neoliberal opera de outra forma. A reestruturação produtiva do capital dos últimos trinta anos no Brasil, contribuiu para o desmonte dos coletivos laborais (ALVES, 2013). Com a proliferação da "mídia pós-alfabética” (as mídias da Internet, as redes sociais da infosfera) (BERARDI, 2007), o espaço público e as coletividades políticas e ainda a noção de cidadania, foram redimensionadas, com a implosão do próprio sentido da democracia representativa (OLIVEIRA; RIZEK, 2007).

O capital alavancou, com o infosfera e suas redes sociais, a manipulação reflexiva, não apenas por meio da "captura" da subjetividade (ALVES, 2013), mas reordenando formas de sociabilidades e (de)formando a produção de individualidades humanas, principalmente na sua dimensão cognitiva (como ocorre com a instrumentalização ideológica da pós-verdade). Desse modo, a reestruturação produtiva do capital e a crise do mundo social do trabalho, com a crise do sindicalismo e dos partidos socialistas e comunistas e, por fim, o surgimento da nova esfera de manipulação social, a Internet e as redes sociais, alteram de vez a função dos intelectuais. Podemos inclusive afirmar que existe uma "crise dos intelectuais" - no sentido de Gramsci (1985) -, tendo em vista as mudanças qualitativamente novas na materialidade da difusão ideológica. No caso do Brasil, com o lastro histórico da sua miséria democrática, tais transformações estruturais do capitalismo global contribuem para a explicitação dos limites efetivos da democracia liberal-representativa. 
As mídias da infosfera põem novas determinações na organização da cultura individualista de mercado. Com o Estado neoliberal no Brasil, surgiu uma nova organização da cultura da manipulação, que alimenta as formas de "miséria da razão" (COUTINHO, 1972) e de barbárie social, intrínsecas à nova razão neoliberal do mundo (DARDOT; LAVAL, 2016), dissolvendo em si e para si, as formas clássicas da ação intelectual-política que foram repostas na época da redemocratização brasileira por meio de organismos coletivos. A natureza da crise do Estado brasileiro diz respeito à crise da sociedade política (crise de representatividade) e à crise da sociedade civil (crise dos organismos coletivos de negociação: sindicato, associações e partidos) face à nova materialidade sociometabólica do tecnocapitalismo. Entretanto, a crise do Estado brasileiro é também crise de organização da cultura democrática e do próprio espaço público, tendo o ataque e o ódio à democracia (RANCIÈRE, 2014) sido um elemento da nova política de crise do capitalismo global.

\section{Referências}

ALVES, Giovanni. A pulsão golpista da miséria política brasileira. In: PRONER, Carol; CITTADINO, Gisele; TONEMBAUM, Marcio; RAMOS FILHO, Wilson (org.). A resistência ao Golpe de 2016. Bauru: Projeto editorial Praxis: Instituto de Defesa da Classe Trabalhadora, 2016.

ALVES, Giovanni. Dimensões da precarização do trabalho: ensaios de sociologia do trabalho. Bauru: Projeto editorial Praxis, 2013.

ALVES, Giovanni. O duplo negativo do capital: um ensaio sobre a crise do capitalismo global. Bauru: Projeto editorial Praxis, 2018.

ALVES, Giovanni. Trabalho e subjetividade: o espírito do toyotismo na era do capitalismo manipulatório. São Paulo: Boitempo editorial, 2011.

ANTUNES, Ricardo. O privilégio da servidão: o novo proletariado de serviços da era digital. São Paulo: Boitempo, 2018.

BAUMANN, Zygmunt. Modernidade líquida. Rio de Janeiro: Jorge Zahar Editor, 2001. 
BELLER, Jonathan. Informatic labor in the age of computational capital. [S.I.]: Lateral 5.1, 2016. Disponível em: https://goo.gl/HnrP7S. Acesso em: 3 out. 2018.

BERARDI “BIFO”, Franco. Fenomenología del fin - sensibilidad e mutación cognitiva. Madri: Caja Negra editora, 2017.

BERARDI “BIFO”, Franco. Generación post-alfa: patologías y imaginarios en el semiocapitalismo. Buenos Aires: Tinta Limón, 2007.

BYUNG-CHUL, Han. No enxame: reflexões sobre o digital. Lisboa: Relógio D’Água Editores, 2013.

CAPTOLOGIA. In: In: WIKIPEDIA: the free encyclopedia. San Francisco, CA: Wikimedia Foundation, 2010. Disponível em: https://en.wikipedia.org/wiki/Captology. Acesso em 29 maio 2020.

CASTELLS, Manuel. A sociedade em rede. (A era da informação: Sociedade e cultura; V. 1). São Paulo: Paz e Terra, 1999.

CASTELLS, Manuel. Ruptura: a crise da democracia liberal. Rio de Janeiro: Jorge Zahar Editores, 2015.

CASTELLS, Manuel. A galáxia da internet. Rio de Janeiro: Jorge Zahar Editores, 2001.

CASTELLS, Manuel. O integralismo de Plínio Salgado: forma de regressividade no capitalismo hiper-tardio. São Paulo: Livraria Ciências Humanas, 1978.

CHASIN, José. A miséria brasileira: 1964-1994: do golpe militar à crise social. São Paulo: Edições Ad Hominem, 1999.

COUTINHO, Carlos Nelson. Cultura e sociedade no Brasil: ensaios sobre ideias e formas. São Paulo: Editora Expressão Popular, 2011.

COUTINHO, Carlos Nelson. Gramsci: um estudo sobre seu pensamento político. São Paulo: Editora Campus, 1989.

COUTINHO, Carlos Nelson. O Estruturalismo e a Miséria da Razão. $1^{\text {a }}$ ed. São Paulo: Ed. Paz e Terra, 1972.

COUTINHO, Eduardo Granja; FREIRE FILHO, João; PAIVA, Raquel. Mídia e poder: ideologia, discurso e subjetividade. Rio de Janeiro: Mauad X, 2014. 
DANTAS, Marcos. Semiótica da mercadoria. Revista Eptic, São Cristóvão, v. 20, n. 1, jan./abr. 2018. Disponível em: https://goo.gl/S44n1P. Acesso em: 3 out. 2018.

DARDOT, Pierre; LAVAL, Christian. A nova razão do mundo: ensaio sobre a sociedade neoliberal. São Paulo: Boitempo editorial, 2016.

FLORENTINO, Manolo; FRAGOSO, João. O arcaísmo como projeto: mercado atlântico, sociedade agrária e elite mercantil em uma economia colonial tardia: Rio de Janeiro, C.1790-C.1840. Rio de Janeiro: Civilização Brasileira, 2001.

FLORIDI, Luciano. A look into the future impact of ICT on our lives. The Information Society, New York: Taylor and Francis, v. 23, n. 1, 2006.

FUCHS, Christian. Class and exploitation on the Internet. In: DIGITAL LABOR: the internet as playground and factor. New York: Ed. Trebor Scholz, 2013.

GORENDER, Jacob. O escravismo colonial. São Paulo: Editora Perseu Abramo, 2016.

GRAMSCI, Antonio. Os intelectuais e a organização da cultura. Rio de Janeiro: Editora Civilização Brasileira, 1985.

HABERMAS, Jurgen. Mudança estrutural da esfera pública. Rio de Janeiro: Tempo Brasileiro, 1984.

HARDMAN, Francisco Foot; LEONARDI, Victor. História da indústria e do trabalho no Brasil. São Paulo: Global, 1982.

HOLZKAMP, Klaus. Grundlegung der psychologie. Frankfurt am Main: Campus Verlag, 1983.

HOLZKAMP-OSTERKAMP, Ute. Grundlagen der psychologischen: motivations-forschung 2 (die besonderheit menschlicher bedürfnisse-problematik und erkenntnisgehalt der Psychoanalyse). 4th ed. Frankfurt am Main: Campus Verlag, 1990.

KEHL, Maria Rita. 18 crônicas e mais algumas. São Paulo: Boitempo, 2011.

KERCKHOVE, Derrick de. A pele da cultura: investigando a nova realidade eletrônica. São Paulo: Annablume, 2009.

KOSIK, Karel. Dialética do concreto. Rio de Janeiro: Zahar Editora, 2015. 
LIPOVETSKY, Gille. A cultura-mundo: resposta a uma sociedade desorientada. São Paulo: Companhia das Letras, 2011.

MARX, Karl. Nova gazeta renana. São Paulo: Educ, 2010.

MARX, Karl. O capital - Crítica da economia política. Livro I. São Paulo: Boitempo, 2013.

MARX, Karl. 018 de brumário de Luís Bonaparte. São Paulo: Boitempo, 2011.

MELLO, João Manuel Cardoso de. O Capitalismo tardio. São Paulo: Editora Unesp, 2009.

MOROZOV, Evgeny. Big Tech: a ascensão dos dados e a morte da política. São Paulo: Ubu Editora, 2018.

NADER, Laura. The phantom fator. In: CHOMSKY, N. et al. The cold war \& the university. New York: The New Press, 1997.

OCDE. The global competition for talent: mobility of the highly skilled. Disponível em: https://www.oecd.org/sti/inno/theglobalcompetitionfortalentmobilityofthehighlyskilled.h tm\#howto. Acesso em: 29 maio 2020.

OLIVEIRA, Francisco de. Crítica à razão dualista/O ornitorrinco. São Paulo: Boitempo, 2013.

OLIVEIRA, Francisco de; RIZEK, Cibele (org.) A era da indeterminação. São Paulo: Boitempo editorial, 2007.

PRADO JÚNIOR, Caio. História econômica do Brasil. São Paulo: Editora Brasiliense, 1985

QUADROS, Waldir. 0 "milagre brasileiro" e a expansão da nova classe média. Campinas: IE/UNICAMP, 1991.

RANCIÈRE, Jacques. O ódio à democracia. São Paulo: Boitempo editorial, 2014.

ROBERTS, Michael; CARCHEDI, Guglielmo (ed.). World in crisis: a global analysis of Marx's law of profitability. Chicago, Illinois: Haymarket books, 2019.

ROSA, Hartmut. Aceleração: a transformação das estruturas na modernidade. São Paulo: Editora Unesp, 2019.

SIEVER, Ray. Doing earth science research during the cold war. In: CHOMSKY, Noam. et al. The cold war \& the university. Nova lorque: The New Press, 1997. 
SEVIGNANI, Sebastian. The development of informational needs and prospects of a needs-based critique of digital capitalismo. Annual Review of Critical Psychology, v. 16, p. 523-543, 2019.

SODRÉ, Nelson Werneck. Capitalismo e revolução burguesa no Brasil. Rio de Janeiro: Graphia, 1997.

SUAREZ-VILLA, Luis. Technocapitalism: a critical perspective on technological innovation and corporatism. Philadelphia: Temple University Press, 2009.

SUAREZ-VILLA, Luis. Globalization and technocapitalism: the political economy of corporate power and technological domination. London: Routledge, 2012.

HORWITZ, Jeff; SEETHARAMAN, Deepa. Facebook Executives Shut Down Efforts to Make the Site Less Divisive. The Wall Street Journal. Nova Iorque. Disponível em: www.wsj.com/articles/facebook-knows-it-encourages-division-top-executives-nixedsolutions- 11590507499?. Acesso em: 29/5/2020.

UNCTAD. Relatório da Economia Digital 2019 - Criação e captura de valor: implicações para os países em desenvolvimento (UNCTAD / DER / 2019). Disponível em: https://unctad.org/en/pages/PublicationWebflyer.aspx?publicationid=2466. Acesso em 28 maio 2020.

WE ARE SOCIAL. Global Digital 2019. Disponível em: https://wearesocial.com/blog/2019/01/ digital-2019-global-internet-use-accelerates. Acesso em: 27 fev. 2020.

ZINN, $\mathrm{H}$. The politics of history in the era of the Cold War. In: CHOMSKY, Noam. et al. The cold war \& the university. Nova lorque: The New Press, 1997.

Recebido em: 12/03/2020

Aprovado em: 10/06/2020

Universidade do Estado de Santa Catarina - UDESC Centro de Ciências Humanas e da Educação - FAED

Revista PerCursos

Volume 21 - Número 45 - Ano 2020 revistapercursos@gmail.com 